\title{
Orientation dependence of swift heavy ion track formation in potassium titanyl phosphate (KTP)
}

\author{
Yu-Jie Ma a,b , Pablo Mota Santiago ${ }^{\mathrm{a}}$, Matias D. Rodriguez ${ }^{\mathrm{a}}$, Felipe Kremer ${ }^{\mathrm{a}}$, Daniel Schauries ${ }^{\mathrm{a}}$, \\ Boshra Afra $^{\mathrm{a}}$, Thomas Bierschenk ${ }^{\mathrm{a}}$, David J Llewellyn ${ }^{\mathrm{a}}$, Fei Lu ${ }^{\mathrm{b}}$, Mark C. Ridgway ${ }^{\mathrm{a}}$, and \\ Patrick Kluth $^{\mathrm{a}}$
}

Corresponding author: Patrick Kluth, email: patrick.kluth@anu.edu.au

a Department of Electronic Materials Engineering, Research School of Physics and Engineering, The Australian National University, Canberra ACT 2601, Australia

${ }^{\mathrm{b}}$ School of Information Science and Engineering, Shandong University, Jinan, Shandong 250100, China

\begin{abstract}
Potassium titanyl phosphate (KTP) crystals in both x-cut and z-cut were irradiated with 185 $\mathrm{MeV} \mathrm{Au}$ ions. The morphology of the resulting ion tracks was investigated using small angle x-ray scattering (SAXS), transmission electron microscopy (TEM) and atomic force microscopy (AFM). SAXS measurements indicate the presence of cylindrical ion tracks with abrupt boundaries and a density contrast of $1 \pm 0.5 \%$ compared to the surrounding matrix, consistent with amorphous tracks. The track radius depends on the crystalline orientation, with $6.0 \pm 0.1 \mathrm{~nm}$ measured for ion tracks along the $\mathrm{x}$-axis and $6.3 \pm 0.1 \mathrm{~nm}$ for those along the z-axis. TEM images in both cross-section and plan-view show amorphous ion tracks with radii comparable to those determined from SAXS analysis. The protruding hillocks covering the sample surface detected by AFM are consistent with a lower density of the amorphous material within the ion tracks compared to the surrounding matrix. Simulations using an
\end{abstract}


inelastic thermal-spike model indicate that differences in the thermal conductivity along the $\mathrm{z}$ - and $\mathrm{x}$-axis can partially explain the different track radii along these directions.

\section{Introduction}

High-energy heavy ions passing through a material can generate narrow trails of damage along their paths, so-called ion tracks. Ion track formation results from inelastic interactions of the projectile ions with the target electrons $[1,2]$ and has been observed in many crystalline and amorphous materials such as semiconductors [3-6], insulators [7-10] and various metals $[11,12]$.

Potassium titanyl phosphate $\left(\mathrm{KTiOPO}_{4}\right.$ or KTP) has a variety of applications spanning from nonlinear optics to electro-optics due to its large non-linear optical coefficients and high optical damage threshold $[13,14]$. The characterisation of the ion track morphology is essential for photonic applications [15] and integrated optical devices with waveguide fabrication by swift heavy ion irradiation (SHII) of KTP [16]. Some studies are available concerning the waveguide properties and ion radiation damage of KTP using Rutherford backscattering spectroscopy/channeling (RBS/C) [17-20], however, a detailed investigation of the ion track morphology in SHII KTP is still lacking.

Small angle x-ray scattering (SAXS) is sensitive to nano-scale density changes and it has been demonstrated to be a powerful technique for the measurement of ion track damage [2124]. It is non-destructive, does not require elaborate sample preparation and measures the entire ion track. Changes in track radii can be determined with very high precision and quick acquisition times enable in-situ studies, for example to identify the track annealing kinetics [25]. 
In this paper, the morphology of ion tracks in SHII KTP is investigated using SAXS, transmission electron microscopy (TEM) and atomic force microscopy (AFM). Results are compared with calculations using an inelastic thermal-spike model.

\section{Experimental}

Single crystalline wafers of both z-cut and x-cut KTP were irradiated with $185 \mathrm{MeV}$ Au ions with fluences of $1 \times 10^{10}$ and $1 \times 10^{11}$ ions $/ \mathrm{cm}^{2}$ at the ANU Heavy Ion Accelerator Facility. Zcut and x-cut KTP refer to the surface normal parallel to the z-axis and x-axis, respectively. Irradiation was performed at normal incidence and room temperature (RT). For the irradiation energy used, the nuclear energy loss is negligible and the electronic energy loss at the surface amounts to approximately $22 \mathrm{keV} / \mathrm{nm}$. All KTP samples had a thickness of $1 \mathrm{~mm}$ before irradiation. After irradiation, samples were mechanically polished from the backside to a thicknesses of $\sim 30 \mu \mathrm{m}$ to reduce parasitic scattering from the substrate during the SAXS experiments. The final thickness exceeds the ion range of $\sim 15 \mu \mathrm{m}$, and as such the entire tracks are contained in the samples.

Transmission SAXS measurements were carried out at the SAXS/WAXS beamline at the Australian Synchrotron [26] using an x-ray energy of $11 \mathrm{keV}$ and a sample-to-detector distance of $1588 \mathrm{~mm}$. For precision alignment of the samples in the x-ray beam, a 3-axis Bruker goniometer was utilized. Measurements were performed at $0^{\circ}, 5^{\circ}$ and $10^{\circ}$ tilt of the ion tracks with respect to the x-ray beam. Scattering from a sample without ion tracks was measured for background removal. For calibration of the scattering intensities to absolute values, a glassy carbon standard was measured [27]. A Pilatus $1 \mathrm{M}$ detector was used for data collection with exposure times between 5 and 10 s. Figure 1 shows scattering images of ion tracks in X-cut KTP irradiated with a fluence of $1 \times 10^{11}$ ions $/ \mathrm{cm}^{2}$. The isotropic image in (a) 
results from the parallel orientation of the ion tracks to the x-ray beam and is consistent with a circular cross section of the tracks [10]. The scattering images of the tracks tilted by $5^{\circ}(\mathrm{b})$ and $10^{\circ}(\mathrm{c})$ resemble slightly curved streaks. These patterns result from the extremely high aspect ratio of the ion tracks that are approximately $15 \mu \mathrm{m}$ long, yet only a few nanometres wide. The intense straight diffraction lines in the SAXS patterns originate from the single crystalline substrate. The scattering signal from ion tracks can be detected in all irradiated samples.

Both plan-view and cross-section transmission electron microscopy (TEM) was performed on the samples using a JEOL $2100 \mathrm{~F}$ microscope operating at $200 \mathrm{kV}$. Standard sample preparation using polishing and ion milling was employed. Under the given measurement conditions, we have not observed any changes of the ion tracks during imaging.

The surface morphology of the irradiated KTP samples was measured using atomic force microscopy (AFM). These measurements were performed under ambient conditions on a Bruker Multimode VIII microscope, operating in tapping mode at a cantilever frequency of $250 \pm 10 \mathrm{kHz}$.

\section{Results and discussion}

\section{Small angle $x$-ray scattering}

For SAXS data analysis, the scattering intensities from the curved streaks of oscillating intensities (see Fig. 1(b), (c)) were extracted. The background produced by scattering from the crystalline matrix was removed by subtracting scattering intensities from narrow radial sectors that exclude the high intensity streaks resulting from the tracks. This was found to be essentially the same as scattering from the un-irradiated sample, yet better enables the subtraction of fluctuations in the background resulting from air scatter. 
Figure 2(a) shows the scattering patterns from ion tracks in KTP irradiated with $185 \mathrm{MeV}$ $\mathrm{Au}^{+}$ions to a fluence of $1 \times 10^{10}$ ions $/ \mathrm{cm}^{2}$ in both $\mathrm{x}$-cut and $\mathrm{z}$-cut and $1 \times 10^{11}$ ions $/ \mathrm{cm}^{2}$ in $\mathrm{x}$-cut. Patterns are shown after background removal and the corresponding model fits (solid lines) are also presented. The strong oscillations in the SAXS intensities of the KTP samples indicate mono-disperse track radii with rather abrupt density transitions between track and matrix material. SAXS measures a large number of tracks (approximately $10^{7}$ ) and the irradiation generates (almost) identical, parallel, well-separated tracks. The measurements thus correspond to the individual track structure, averaging out fluctuations on an atomic scale. The best model to adequately reproduce the experimental data consists of a cylindrical ion track with constant electron density [21]. The corresponding form factor can be expressed as

$$
f(q)=2 \pi L R \Delta \rho \frac{J_{1}(R q)}{q}
$$

where $\mathrm{L}$ is the track length, $\mathrm{R}$ the track radius, $\Delta \rho$ the density contrast between track and matrix, and $\mathrm{q}$ the scattering vector. $\mathrm{J}_{1}$ denotes the first order Bessel function. The change in electron density between the track and matrix is described by a step function. The fits yield a track radius of $6.0 \pm 0.1 \mathrm{~nm}$ for the $\mathrm{x}$-cut $\mathrm{KTP}$ sample and $6.3 \pm 0.1 \mathrm{~nm}$ for the z-cut KTP sample. The uncertainties listed are the fitting errors from the non-linear least squares fits. A narrow Gaussian distribution of the radius was used to account for deviations of the track shape from a perfect cylinder such as the variation of the track radius over the track length resulting from changes in the stopping power and deviations from perfectly sharp track boundaries [22]. The width of this distribution for both samples is $0.9 \pm 0.1 \mathrm{~nm}$. We note that this is not the statistical uncertainty in the track radius. Fig. 2(b) presents the SAXS patterns of both $\mathrm{z}$ - and $\mathrm{x}$-cut in order to visualize the difference between the two. The offset of the SAXS patterns in q of both orientations is clearly apparent in the figure and results in the different fitted track radii. Possible errors related to differences in the experimental setup for 
both samples (for example the sample position) are much smaller than the observed difference in the spectra. While other systematic errors cannot be fully excluded, the samples were measured under identical conditions and as such those can be ruled out to be responsible for the difference as well.

The density change between track and matrix material can be estimated to $1 \pm 0.5 \%$. Track overlap effects can be neglected at the fluences under investigation. This is confirmed estimating the area of modified material $d$ as: $d=1-\exp \left(-\pi R^{2} v\right)$ [28], where $\mathrm{R}$ is the track radius and $v$ the ion fluence. For low ion fluences, the area where ion tracks overlap can then be estimated as $\pi R^{2} v-d$. For a track radius of $6.0 \mathrm{~nm}$ the extent of overlap of the modified area is $2.7 \%$ for a fluence of $1 \times 10^{10}$ ions $/ \mathrm{cm}^{2}$, and $5.6 \%$ for a fluence of $1 \times 10^{11}$ ions $/ \mathrm{cm}^{2}$. Both of these fluences are low enough to neglect track overlap.

As indicated above, the track radius in $\mathrm{x}$-cut and $\mathrm{z}$-cut KTP samples differs by $\sim 5 \%$. This difference in the track radius along two orientations is of the same order of magnitude as that in SHI irradiated quartz samples [29, 30]. As shown in section 4, the different thermal conductivity along different crystal orientations is one factor leading to this difference, which is corroborated by calculations using a thermal-spike model. Additionally, different atomic arrangements along different orientations could also influence ion track formation.

\section{Transmission electron microscopy}

Fig. 3 shows cross-section TEM images of ion tracks in z-cut KTP irradiated to a fluence of $1 \times 10^{11}$ ions $/ \mathrm{cm}^{2}$ in (a) and (c) with different magnifications, as well as plan-view TEM images of ion tracks in z-cut KTP with a fluence of $1 \times 10^{10}$ ions $/ \mathrm{cm}^{2}$ in (d) and (f). The crosssectional TEM images indicate continuous ion tracks with a different contrast to that of the surrounding crystalline matrix. The diffraction pattern in Fig. 3 (b) taken with the electron 
beam parallel to the zone axis of the substrate shows the crystalline structure of the substrate as well as rings confirming the presence of amorphous material, presumably in the ion track. In the plan-view TEM images, the approximately circular tracks consist of an amorphous core region with a rather sharp transition to the crystalline matrix (Fig. 3(d) and (f)). The orientation of the track in this case is parallel to the zone axis, as determined by diffraction (Fig. 3 (e)). Figures 3(d) and 3(f) confirm the ion track overlap effect is negligible under this ion fluence. The track diameter was obtained from the ion tracks shown in Fig. 3(d) and is approximately $13 \pm 2 \mathrm{~nm}$. The uncertainty was estimated based on the somewhat indistinct choice of the track boundaries in the images. Within these uncertainties, the observed track diameter is consistent with the SAXS results. SAXS provides a more reliable value of the track radius, because it measures a larger number of tracks that are well aligned in a bulk sample in comparison with TEM, which is limited to the observation of a small number of tracks localized in a thin sample surface area. Although SAXS is not able to determine if the sign of the density difference of a scattering object is positive or negative, it is plausible to assume that the mass density of amorphous tracks is less than the surrounding crystalline matrix [31]. Consequently, we suggest, that the density of the amorphous tracks is $1 \pm 0.5 \%$ lower than the density of the crystalline matrix. This is also confirmed by the following AFM results.

\section{Atomic force microscopy analysis}

Fig. 4 presents the surface morphology of z-cut KTP irradiated with fluences of $1 \times 10^{10}$ (a) and $1 \times 10^{11}$ ions $/ \mathrm{cm}^{2}(\mathrm{~b})$, as well as that of an unirradiated KTP sample for comparison (c). The virgin KTP has a flat surface with a roughness of $0.2 \mathrm{~nm}$ over an area of $\left(1 \times 1 \mu \mathrm{m}^{2}\right)$. The irradiated KTP surface exhibits conical-shaped hillocks with circular bases (Fig. 4(a) and (b)), which correspond to the ion tracks. The hillocks result as a consequence of out of plane 
expansion of the amorphous material in the track due to a decreased density of the amorphous material with respect to the crystalline phase $[32,33]$. As apparent from the figure, the number of hillocks increases with increasing fluence. The number of hillocks per unit area of the low fluence sample amounts to approximately $1.5 \times 10^{10}$ hillocks $/ \mathrm{cm}^{2}$, in agreement with the nominal fluence $\sim 1 \times 10^{10}$ ions $/ \mathrm{cm}^{2}$ (within uncertainties). It indicates each ion produces a track and the effect of overlap is negligible. Similar observations were obtained from AFM measurements of the x-cut samples.

\section{Thermal-spike model}

To estimate the local temperature around the ion trajectory of a heavy ion, we utilize an inelastic thermal-spike (i-TS) model. In this model, the energy lost by the ions traversing the solid is deposited into the electronic system and subsequently transferred to the atomic system by electron-phonon interactions. The process can be modelled using two coupled heat-diffusion equations [34-36]:

$$
\begin{gathered}
C_{e}(T) \frac{\partial T_{e}}{\partial t}=\nabla\left[K_{e}(T) \nabla T_{e}\right]+A(r, t)-g\left(T_{e}-T_{a}\right), \\
\rho_{a} C_{a}(T) \frac{\partial T_{a}}{\partial t}=\nabla\left[K_{a}(T) \nabla T_{a}\right]+g\left(T_{e}-T_{a}\right),
\end{gathered}
$$

where $T_{e}, T_{a}, C_{e}(T), C_{a}(T), K_{e}(T)$, and $K_{a}(T)$ are the temperatures, the specific heats, and the thermal conductivities of the electronic and atomic subsystems, respectively. $\mathrm{g}$ is the coupling parameter governing the strength of the electron-phonon interaction, $\rho_{\mathrm{a}}$ is the mass density of KTP and A(r,t) the energy given to the electrons by the ion at a time $t$ and a distance $r$ from the centre of the ion path. This takes the form: $A(r, t)=A_{0} D(r) \exp \left[-(t-\tau)^{2} / 2 \tau^{2}\right]$, where $\tau$ is the mean flight time of the delta electrons, which is assumed to be of the order of $10^{-15} \mathrm{~s}$. $\mathrm{A}_{0}$ is a normalization constant for the total deposited energy such that it is equivalent to $\mathrm{S}_{\mathrm{e}}$. $\mathrm{D}(\mathrm{r})$ is the initial spatial energy distribution of the electrons and calculated using the 
formalism by Waligorski et al. [38] for Au ions with an energy of $185 \mathrm{MeV}$. The resulting energy distribution is shown in Fig. 5 (a) where it is apparent that more than $90 \%$ of the energy is deposited within $1 \mathrm{~nm}$ radial distance from the ion trajectory.

Due to the dielectric nature of KTP, we adopt the approach proposed in [39], where the electronic system behaves linearly at temperatures below the band gap, where only a fraction of the electrons are ionized, and as a free electron gas for temperatures above the band gap. The relation between electronic specific heat $C_{e}$ and temperature $T_{e}$ used in this work is thus:

$$
C_{e}(T)= \begin{cases}\left(\frac{\pi^{2} k_{B} n_{a}}{2}\right)\left(\frac{T_{e}}{T_{g}}\right) & T_{e} \leq \frac{3}{\pi^{2}} T_{g} \\ \frac{3 k_{B} n_{a}}{2} & T_{e}>\frac{3}{\pi^{2}} T_{g}\end{cases}
$$

Here $T_{g}$ is the temperature corresponding to the bandgap energy, $E_{g}=k_{B} T_{g}=4.9 e V$ for KTP. $k_{B}$ and $\mathrm{n}_{\mathrm{a}}$ are the Boltzmann constants and atomic density, respectively. The electron-phonon coupling constant $g$ is related to the mean free path $\lambda$ through the formula $\lambda^{2}=K_{e} / g$, where $\lambda$ is considered as an adjustable parameter. For the insulator material KTP with band gap of $4.9 \mathrm{eV}, \lambda$ is assumed to be $4 \mathrm{~nm}[40,41]$.

For the lattice system, the specific heat was assumed to be constant. The atomic thermal conductivity of KTP varies along different crystallographic directions with $\mathrm{K}_{\mathrm{x}}=2.0 \times 10^{-2}$, $\mathrm{K}_{\mathrm{y}}=3.0 \times 10^{-2}$ and $\mathrm{K}_{\mathrm{z}}=3.3 \times 10^{-2} \mathrm{Wcm}^{-1} \mathrm{~K}^{-1}$ (the subscript denoting the crystallographic direction). For the calculations of tracks parallel to the $\mathrm{z}$-axis (x-axis), the average of $\mathrm{K}_{\mathrm{x}}$ and $\mathrm{K}_{\mathrm{y}}\left(\mathrm{K}_{\mathrm{y}}\right.$ and $\left.\mathrm{K}_{\mathrm{z}}\right)$ was used [42].

By using the radial energy distribution as the energy input in the heat-diffusion equation for the electronic system shown in Fig 5 (a) we calculated the temperature profile of the lattice at different times. 
The electrons near the ion trajectory are excited to very high temperatures on an extremely short time scale. A fraction of their energy is then transferred to the atoms by electronphonon interactions, which causes the local temperature to increase above the melting point of the material. The lattice temperature decreases with increasing distance from the ion path, and the ion track dimension is related to the largest distance where the temperature exceeds the melting point of $\mathrm{T}_{\mathrm{m}}=1423 \mathrm{~K}$. Due to the lack of information available for the latent heat of melting for this material, we estimated this value by averaging the latent heat for the elemental composition resulting in $518.85 \mathrm{~J} / \mathrm{cm}^{3}$, which probably underestimates the real value. The calculations yield a radius of $\sim 5.8 \mathrm{~nm}$ and $5.9 \mathrm{~nm}$ for tracks along the $\mathrm{x}$-direction (x-cut) z-direction (z-cut), respectively. Fig. 5(b) presents the simulated evolution of the lattice temperature versus time at various distances between 2 and $6 \mathrm{~nm}$ from the ion path in both x-cut and z-cut KTP irradiated with $185 \mathrm{MeV} \mathrm{Au}{ }^{+}$ions. The difference in the patterns of $\mathrm{x}$-cut and $\mathrm{z}$-cut results from the different thermal conductivities of the different crystal orientations. As apparent from Fig. 5 (b), the effect becomes important at the later stages of the thermal spike, during the cooling phase. The inset in Fig. 5 (b) shows a magnification of this area, which highlights these differences. The calculated difference in the track radii is approximately $2 \%$, indicating that the thermal conductivity makes a significant contribution to the observed $5 \%$ difference in the ion track radii along both orientations. Anisotropies in other physical properties of KTP such as mechanical and piezoelectric properties [43, 44] are also likely to contribute to this effect.

It is important to note that this effect should be present in most crystalline materials, as they often possess different values for the thermal conductivity in different crystallographic directions. This could possibly explain similar differences observed in quartz $[29,30]$ and apatite [45]. To resolve the small magnitude of such differences, however, requires accurate measurements of the track radii such as those attainable by SAXS. 


\section{Conclusion}

The morphology and radius of ion tracks generated by $185 \mathrm{MeV}$ Au ions in KTP has been investigated by means of synchrotron SAXS, TEM and AFM. SAXS results indicate ion track radii depend on the crystalline orientation. The radius obtained from SAXS is consistent with that from TEM results, yet the higher precision of SAXS enables us to resolve a $5 \%$ difference between radii in $\mathrm{z}$ - and $\mathrm{x}$-cut samples. High-resolution TEM and AFM provide clear evidence that the tracks in KTP are amorphous with approximately circular crosssection, and of lower density than the surrounding crystalline matrix. Calculations using an inelastic thermal-spike model are in good agreement with the experimental results and indicate that differences in the thermal conductivity along the $\mathrm{z}$ - and $\mathrm{x}$-axes contribute significantly to the difference in track radii observed along these directions.

\section{Acknowledgements}

The authors acknowledge the National Nature Science Foundation of China (Grant No.51272135) and the Australian Research Council for financial support and thank the staff of the ANU Heavy Ion Accelerator Facility for technical support. Part of this research was undertaken on the SAXS/WAXS beamline at the Australian Synchrotron, Victoria, Australia. 


\section{References}

1. A. Dunlop, D. Lesueur: Damage creation via electronic excitations in metallic targets part I: Experimental results. Radiat. Effects Defects Solids 126, 123 (1993).

2. A. Meftah, J. M. Costantini, N. Khalfaoui, S. Boudjadar, J. P. Stoquert, F. Studer, M. Toulemonde: Experimental determination of track cross-section in $\mathrm{Gd}_{3} \mathrm{Ga}_{5} \mathrm{O}_{12}$ and comparison to the inelastic thermal spike model applied to several materials. Nucl. Instr. and Meth. B 237, 563 (2005).

3. M. Levalois, P. Bogdanski, M. Toulemonde: Induced damage by high energy heavy ion irradiation at the GANIL accelerator in semiconductor materials. Nucl. Instr. and Meth. B 63, 14 (1992).

4. W. Wesch, A. Kamarou, E. Wendler: Effect of high electronic energy deposition in semiconductors. Nucl. Instr. and Meth. B 225, 111 (2004).

5. M. C. Ridgway, T. Bierschenk, R. Giulian, B. Afra, M. D. Rodriguez, L. L. Araujo, A. P. Byrne, N. Kirby, O. H. Pakarinen, F. Djurabekova, K. Nordlund, M. Schleberger, O. Osmani, N. Medvedev, B. Rethfeld, P. Kluth: Tracks and Voids in Amorphous Ge Induced by Swift Heavy-Ion Irradiation. Phys. Rev. Lett. 110, 245502 (2013).

6. T. Bierschenk, R. Giulian, B. Afra, M. D. Rodriguez, D. Schauries, S. Mudie, O. H. Pakarinen, F. Djurabekova, K. Nordlund, O. Osmani, N. Medvedev, B. Rethfeld, M. C. Ridgway, P. Kluth: Latent ion tracks in amorphous silicon. Phys. Rev. B 88, 174111 (2013).

7. C. Trautmann, M. Toulemonde, K. Schwartz, J. M. Costantini, A. Mueller: Damage structure in the ionic crystal LiF irradiated with swift heavy ions. Nucl. Instr. and Meth. B 164-165, 365 (2000). 
8. M. Toulemonde, E. Balanzat, S. Bouffard, J. C. Jousset: Structural modifications induced by electronic energy deposition during the slowing down of heavy ions in matter. Nucl. Instr. and Meth. B 39, 1 (1989).

9. M. Toulemonde, C. Trautmann, E. Balanzat, K. Hjort, A. Weidinger: Track formation and fabrication of nanostructures with MeV-ion beams. Nucl. Instr. and Meth. B 216, 1 (2004).

10. A. Meftah, F. Brisard, J. M. Costantini, E. Dooryhee, M. Hage-Ali, M. Hervieu, J. P. Stoquert, F. Studer, M. Toulemonde: Track formation in $\mathrm{SiO}_{2}$ quartz and the thermalspike mechanism. Phys. Rev. B 49, 12457 (1994).

11. A. Barbu, A. Dunlop, D. Lesueur, R. S. Averback: Latent Tracks Do Exist in Metallic Materials. Europhys. Lett. 15, 37 (1991).

12. C. Dufour, A. Audouard, F. Beuneu, J. Dural, J. P. Girard, A. Hairie, M. Levalois, E. Paumier, M. Toulemonde: A high-resistivity phase induced by swift heavy-ion irradiation of Bi: a probe for thermal spike damage?. J. Phys.: Condens. Matter 5, 4573 (1993).

13. Y. S. Liu, D. Dentz, R. Belt: High-average-power intracavity second-harmonic generation using $\mathrm{KTiOPO}_{4}$ in an acousto-optically Q-switched Nd:YAG laser oscillator at $5 \mathrm{kHz}$. Opt. Lett. 9, 76 (1984).

14. F. C. Zumsteg, J. D. Bierlein, T. E. Gier: $\mathrm{K}_{\mathrm{x}} \mathrm{Rb}_{1-\mathrm{x}} \mathrm{TiOPO}_{4}$ : A new nonlinear optical material. J. Appl. Phys. 47, 4980 (1976).

15. F. Chen: Micro- and submicrometric waveguiding structures in optical crystals produced by ion beams for photonic applications. Laser Photon. Rev. 6, 622 (2012).

16. Th. Opfermann, Th. Höche, S. Klaumünzer, W. Wesch: Formation of amorphous tracks in $\mathrm{KTiOPO}_{4}$ during swift heavy ion implantation. Nucl. Instr. and Meth. B 166-167: 954 (2000). 
17. P. Bindner, A. Boudrioua, J. C. Loulergue, P. Moretti: Formation of planar optical waveguides in potassium titanyl phosphate by double implantation of protons. Appl. Phys. Lett. 79, 2558 (2001).

18. Th. Opfermann, Th. Höche, W. Wesch: Radiation damage in $\mathrm{KTiOPO}_{4}$ by ion implantation of light elements. Nucl. Instrum. Methods Phys. Res. B 166-167, 309 (2000).

19. W. Wesch, Th. Opfermann, T. Bachmann: Radiation damage in $\mathrm{KTiOPO}_{4}$ by ion implantation of light elements. Nucl. Instrum. Methods Phys. Res. B 141, 338 (1998).

20. K. M. Wang, B. R. Shi: Waveguide formation of $\mathrm{KTiOPO}_{4}$ by multienergy $\mathrm{MeV} \mathrm{He}^{+}$ implantation. J. Mater. Res. 11, 1333 (1996).

21. M. D. Rodriguez, B. Afra, C. Trautmann, M. Toulemonde, T. Bierschenk, J. Leslie, R. Giulian, N. Kirby, P. Kluth, J. Non-Cryst. Solid 358, 571 (2012).

22. P. Kluth, C.S. Schnohr, O. H. Pakarinen, F. Djurabekova, D.J. Sprouster, R. Giulian, M. C. Ridgway, A. P. Byrne, C. Trautmann, D. J. Cookson, K. Nordlund, M. Toulemonde: Fine Structure in Swift Heavy Ion Tracks in Amorphous $\mathrm{SiO}_{2}$. Phys. Rev. Lett. 101, 175503 (2008).

23. P. Kluth, C. S. Schnohr, D. J. Sprouster, A. P. Byrne, D. J. Cookson, M. C. Ridgway: Measurement of latent tracks in amorphous $\mathrm{SiO}_{2}$ using small angle X-ray scattering. Nucl. Instrum. Methods Phys. Res. B 266, 2994 (2008).

24. P. Kluth, O. H. Pakarinen, F. Djurabekova, R. Giulian, M. C. Ridgway, A. P. Byrne, K. Nordlund: Nanoscale density fluctuations in swift heavy ion irradiated amorphous $\mathrm{SiO}_{2}$. J. Appl. Phys. 110, 123520 (2011).

25. B. Afra, M. Lang, M. D. Rodriguez, J. Zhang, R. Giulian, N. Kirby, R. C. Ewing, C. Trautmann, M. Toulemonde, P. Kluth: Annealing kinetics of latent particle tracks in Durango apatite. Phys. Rev. B 83, 064116 (2011). 
26. N. M. Kirby, S. T. Mudie, A. M. Hawley, D. J. Cookson, H. D. T. Mertens, N. Cowieson, and V. Samardzic-Boban: A low-background-intensity focusing small-angle X-ray scattering undulator beamline. J. Appl. Cryst. 46, 1670 (2013).

27. F. Zhang, J. Ilavsky, G. G. Long, J. P. G. Quintana, A. J. Allen, and P. R. Jemian: Glassy Carbon as an Absolute Intensity Calibration Standard for Small-Angle Scattering. Metall. Mater. Trans. A 41A, 1151 (2010).

28. C. Riedel, R. Spohr: Statistical properties of etched nuclear tracks I. Analytical Theory and Computer Simulation. Radiat. Effects 42, 69 (1979).

29. D. Schauries, M. Lang, O. H. Pakarinen, S. Botis, B. Afra, M. D. Rodriguez, F. Djurabekova, K. Nordlund, D. Severin, M. Bender, W. X. Li, C. Trautmann, R. C. Ewing, N. Kirby, P. Kluth: Temperature dependence of ion track formation in quartz and apatite. J. Appl. Cryst. 46, 1558 (2013).

30. D. Schauries, A. A. Leino, B. Afra, M. D. Rodriguez, F. Djurabekova, K. Nordlund, N. Kirby, C. Trautmann, P. Kluth: Orientation dependent annealing kinetics of ion tracks in c-SiO 2 . J. Appl. Phys. 118, 224305 (2015).

31. M. D. Rodriguez, W. X. Li, F. Chen, C. Trautmann, T. Bierschenk, B. Afra, D. Schauries, R. C. Ewing, S. T. Mudie, P. Kluth: SAXS and TEM investigation of ion tracks in neodymium-doped yttrium aluminium garnet. Nucl. Instr. and Meth. B 326, 150 (2014).

32. V. A. Skuratov, S. J. Zinkle, A. E. Efimov, K. Havancsak: Swift heavy ion-induced modification of $\mathrm{Al}_{2} \mathrm{O}_{3}$ and $\mathrm{MgO}$ surfaces. Nucl. Instr. and Meth. B 203, 136 (2003).

33. S. M. M. Ramos, N. Bonardi, B. Canut, S. Bouffard, S. Della-Negra: Damage creation in a $-\mathrm{Al}_{2} \mathrm{O}_{3}$ by $\mathrm{MeV}$ fullerene impacts. Nucl. Instr. and Meth. B 143, 319 (1998).

34. Z. G. Wang, C. Dufour, E. Paumier, M. Toulemonde: The $S_{e}$ sensitivity of metals under swift-heavy-ionirradiation: a transient thermal process. J. Phys.: Condens. Matter 6, 6733 (1994). 
35. M. Toulemonde, E. Paumier, J. M. Costantini, Ch. Dufour, A. Meftah, F. Studer: Track creation in $\mathrm{SiO}_{2}$ and $\mathrm{BaFe}_{12} \mathrm{O}_{19}$ by swift heavy ions: A thermal spike description. Nucl. Instr. and Meth. B 116, 37 (1996).

36. M. Toulemonde, C. Dufour, A. Meftah, E. Paumier: Transient thermal processes in heavy ion irradiation of crystalline inorganic insulators. Nucl. Instr. and Meth. B 116-167, $903(2000)$.

37. N. W. Ashcroft and N. D. Mermin, 1976 Solid State Physics (New York: Holt Reinhart and Winston).

38. M. P. R. Waligórski, R. N. Hamm and R. Katz: The radial distribution of dose around the path of a heavy ion in liquid water. Nucl. Tracks Radiat. Meas. 11, 309 (1986).

39. Ch. Dufour, V. Khomenkov, G. Rizza, M. Toulemonde: Ion-matter interaction: the threedimensional version of the thermal spike model. Application to nanoparticle irradiation with swift heavy ions. J. Phys. D: Appl. Phys. 45, 065302 (2012).

40. Y. V. Martynenko, Y. N. Yavlinskii: Cooling of the electron gas of a metal at high temperatures. Sov.Phys.-Dokl. 28, 391 (1983).

41. F. F. Komarov: Defect and track formation in solids irradiated by superhigh-energy ions. Physics-Uspekhi 46, 1253 (2003).

42. T. Hikita (2004), Y. Shiozaki, E. Nakamura, T. Mitsui (ed.) SpringerMaterials 35A-6: 10-11, 13, 15-16 KTiOPO4[F]: 10 Light scattering, 11 Conduction, 13 NMR, ESR, 15 Domains, 16 Miscellanea, Landolt-Börnstein - Group III Condensed Matter 36B1 (Inorganic Substances other than Oxides. Part 1: SbSI family ... TAAP) (Springer-Verlag Berlin Heidelberg (C2004)

43. D. K. T. Chu, J. D. Bierlein, G. Hunsperger: Piezoelectric and acoustic properties of potassium titanyl phosphate (KTP) and its isomorphs. IEEE Trans. Ultrason., Ferroelect., Freq. Control 39, 683 (1992). 
44. D. K. T. Chu, J. D. Bierlein, G. Hunsperger: Piezoelectric, elastic, and ferroelectric properties of $\mathrm{KTiOPO}_{4}$ and its isomorphs. Frequency Control Symposium, 1992. 46th., Proceedings of the 1992 IEEE, 732 (1992).

45. W. Li, P. Kluth, D. Schauries, M. D. Rodriguez, M. Lang, F. Zhang, M. Zdorovets, C. Trautmann, and R. C. Ewing: Effect of orientation on ion track formation in apatite and zircon. American Mineralogist 99, 1127 (2014). 


\section{Figure captions:}

Fig. 1: SAXS images of $\mathrm{x}$-cut KTP irradiated with $185 \mathrm{MeV}$ Au ions to a fluence of $1 \times 10^{11}$ ions $/ \mathrm{cm}^{2}$ with the tracks (a) collinear with the x-ray beam, showing an isotropic scattering pattern, (b) tilted by $5^{\circ}$ and (c) tilted by $10^{\circ}$ with respect to the x-ray beam.

Fig. 2: (a) SAXS intensities as a function of scattering vector q for tracks in both $\mathrm{x}$-cut and zcut KTP irradiated with ion fluences of $1 \times 10^{10}$ and $1 \times 10^{11}$ ions $/ \mathrm{cm}^{2}$. The solid lines are the corresponding fits to the theoretical model. The patterns are offset for clarity. (b) SAXS patterns of both x-cut and z-cut KTP samples irradiated under identical conditions.

Fig. 3. Cross-section TEM images (a) and (c), and corresponding electron diffraction image (b) of ion tracks in z-cut KTP irradiated with $185 \mathrm{MeV}$ Au ions at fluence of $1 \times 10^{11}$ ions $/ \mathrm{cm}^{2}$; plan-view TEM images of ion tracks in z-cut KTP irradiated with $1 \times 10^{10}$ ions $/ \mathrm{cm}^{2}$ in (d) and (f) and corresponding electron diffraction image (e).

Fig. 4. AFM surface plots of $185 \mathrm{MeV} \mathrm{Au}^{+}$-irradiated KTP with fluences of $1 \times 10^{10}$ (a) and $1 \times 10^{11}$ ions $/ \mathrm{cm}^{2}$ (b), and that of unirradiated KTP for comparison (c).

Fig. 5. (a) Radial distribution of energy deposited around the ion path of KTP irradiated with $185 \mathrm{MeV} \mathrm{Au}$ ions. (b) Simulated evolution of the lattice temperature versus time at various distances $(2,5,5.5,5.8$, and $6 \mathrm{~nm})$ from the ion path in both $\mathrm{x}$-cut (solid lines) and $\mathrm{z}$-cut (dotted lines) KTP irradiated by $185 \mathrm{MeV} \mathrm{Au}{ }^{+}$-ions. $\mathrm{T}_{\mathrm{m}}=1423 \mathrm{~K}$ corresponds to the melting 
temperature of KTP. The inset shows a magnification of the later stages of the lattice temperature to highlight the differences for the two crystal cuts. 
Figure 1:

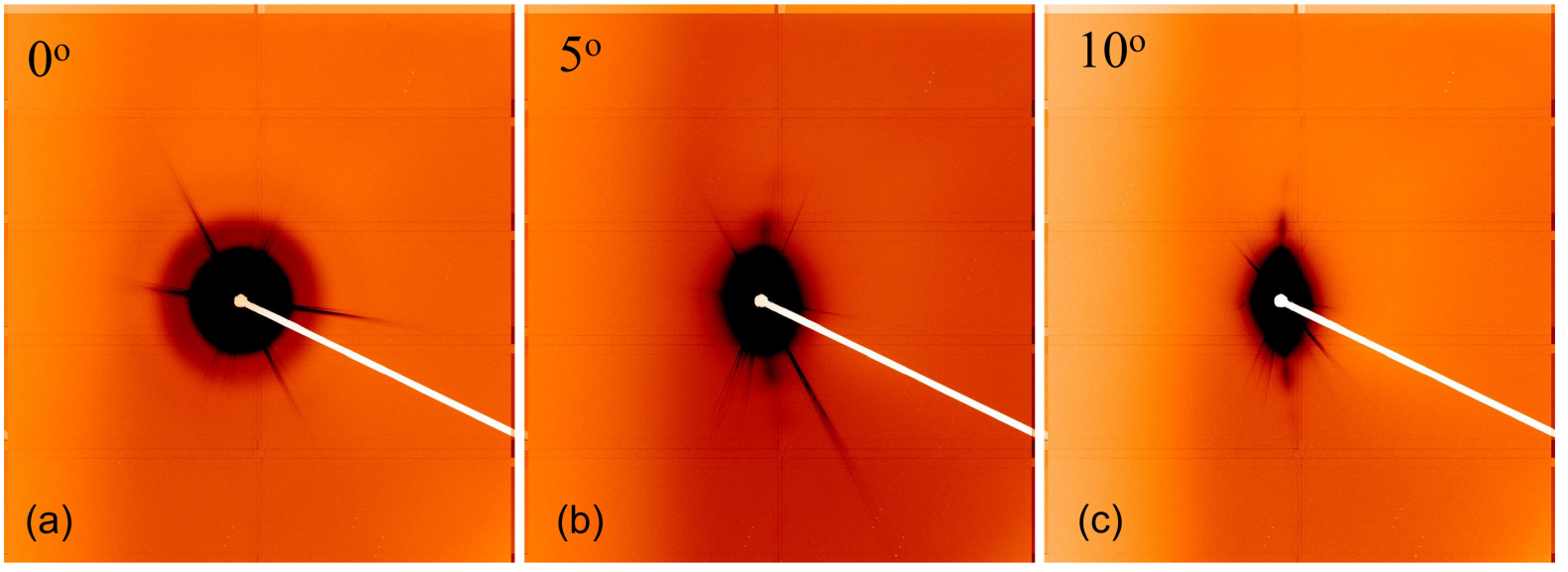


Figure 2:
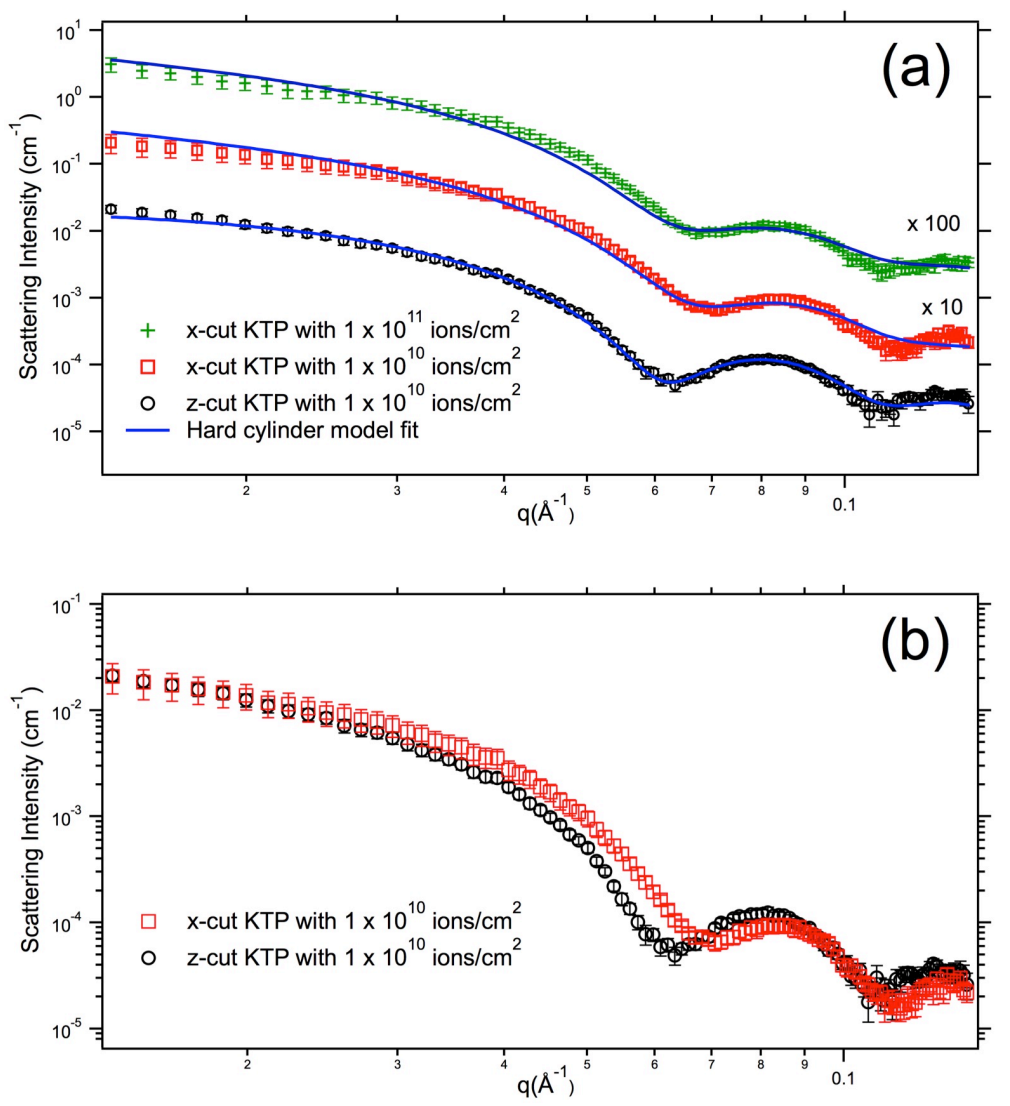
Figure 3:

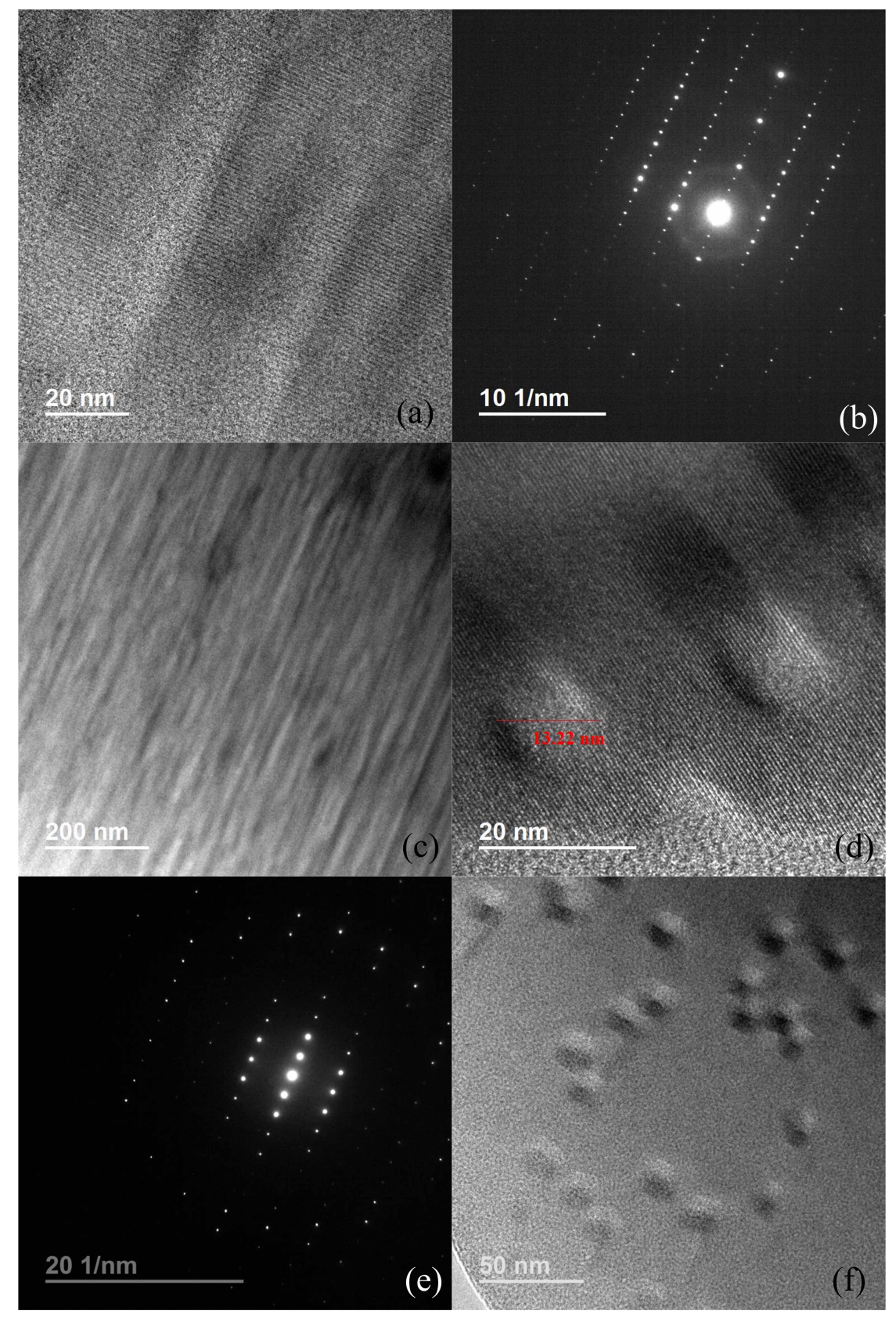


Figure 4:

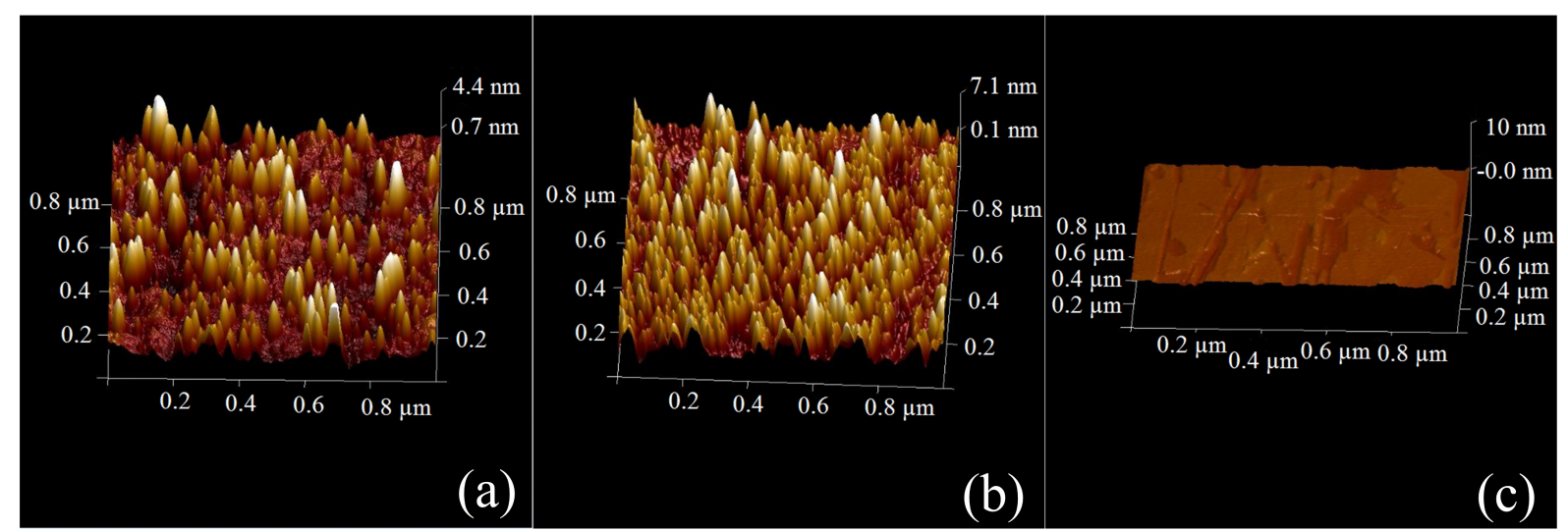


Figure 5:

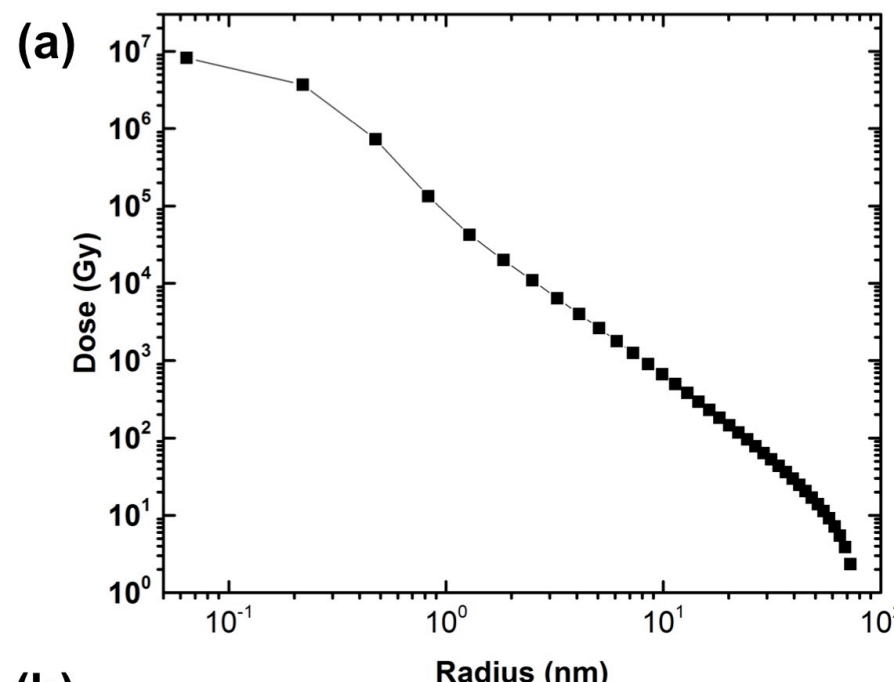

(b)

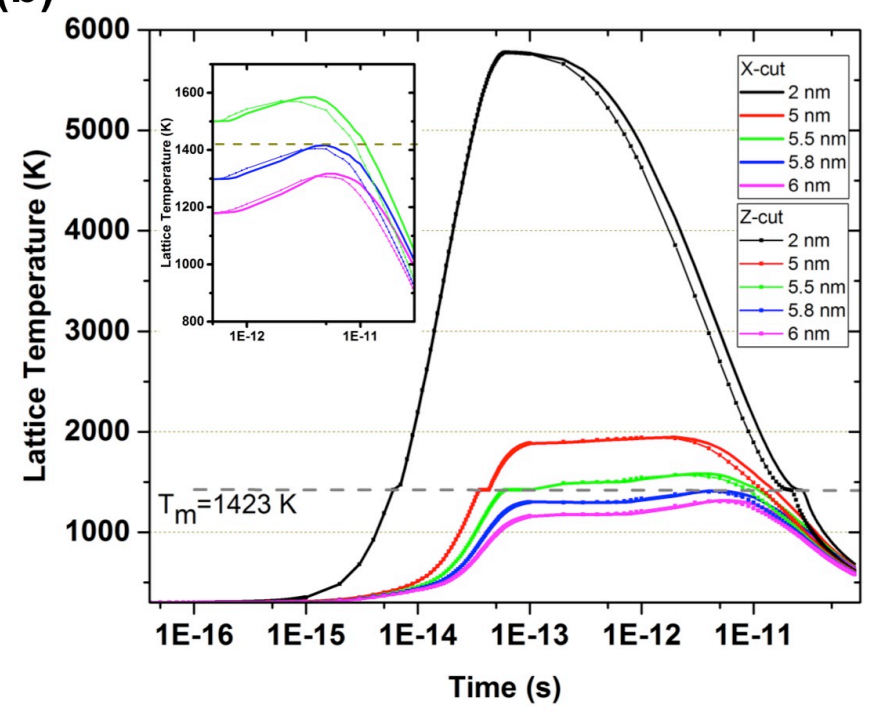

